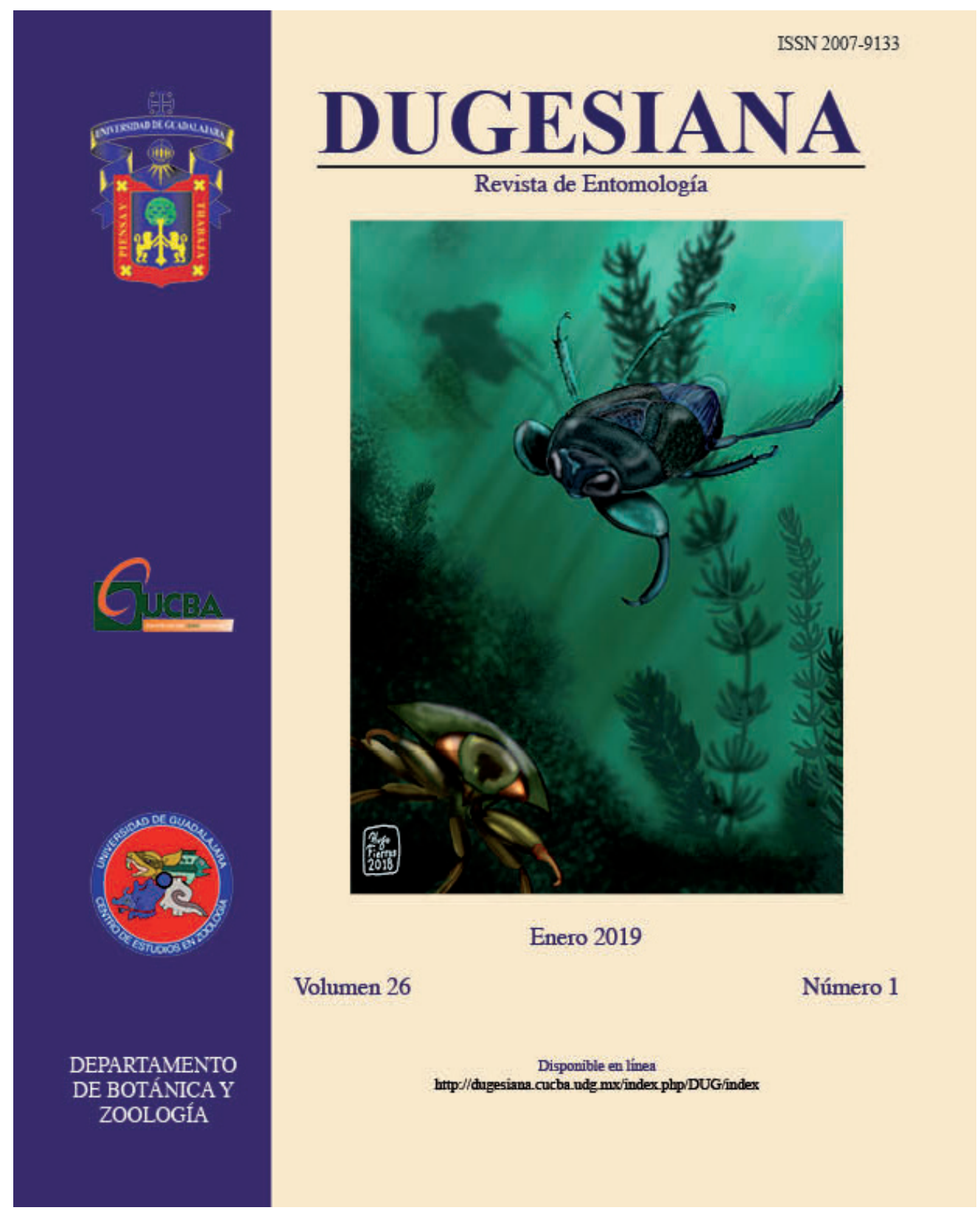

DUGESIANA, Año 26, No.1, 2019 (primer semestre de 2019) es una publicación Semestral editada por la Universidad de Guadalajara, a través del Centro de Estudios en Zoología, por la División de Ciencias Biológicas y Ambientales, CUCBA. Km. 15.5 carr. a Nogales, Predio Las Agujas s/n, Nextipac, C.P. 45100. Zapopan, Jalisco, México. Tel. 37771150, http://dugesiana.cucba.udg.mx/index.php/DUG/index, glenusmx@gmail.com, Editor responsable: José Luis Navarrete Heredia. Reserva de Derechos al Uso Exclusivo 04-2009-062310115100-203, ISSN: 2007-9133, otorgados por el Instituto Nacional del Derecho de Autor. Responsable de la última actualización de este número: José Luis Navarrete Heredia, Editor y Ana Laura González-Hernández, Asistente Editorial. Fecha de la última modificación 1 de enero de 2019, con un tiraje de un ejemplar.

Las opiniones expresadas por los autores no necesariamente reflejan la postura del editor de la publicación.

Queda estrictamente prohibida la reproducción total o parcial de los contenidos e imágenes de la publicación sin previa autorización de la Universidad de Guadalajara. 


\section{Registro de Diversinervus elegans Silvestri (Hymenoptera: Encyrtidae) para la ciudad de Bogotá, Colombia \\ Record of Diversinervus elegans Silvestri (Hymenoptera: Encyrtidae) Bogota, Colombia Juliana Durán Prieto ${ }^{1 *}$ y Valentina Ocampo ${ }^{1}$}

${ }^{1}$ Subdirección Científica, Jardín Botánico de Bogotá José Celestino Mutis, Avenida Calle 63 No. 68-95, Bogotá, Colombia.*Autor por correspondencia: jduran@jbb.gov.co

Diversinervus elegans Silvestri (1915) es una especie de avispa parasitoide de la familia Encyrtidae (Hymenoptera: Chalcidoidea) perteneciente a la subfamilia Encyrtinae, a la tribu Cheiloneurini y al género Diversinervus Silvestri (1915), el cual incluye otras once especies a nivel mundial (Noyes, 2018). Cheiloneuroides bicristatus Girault, 1915, Diversinervus intermedius Hayat, Alam y Agarwal, 1975 y D. meridio son sinonimias de esta especie (Trjapitzin et al. 2008; Noyes 2018).

Diversinervus elegans es originaria de África y Asia pero actualmente se distribuye también en la región neotropical. En el Neotrópico D. elegans se ha registrado en Honduras, México, Cuba, Brasil, Perú y Colombia (Trjapitzin y RuízCancino 1997, De Santis y Fidalgo 1994). Es reconocida como agente biocontrolador de cóccidos de los géneros Saissetia Deplanche, 1858, Parasaissetia Takahashi 1955, Coccus Linnaeus, 1758, Ceroplastes Gray, 1828, Pulvinaria Targioni Tozzetti, 1866, Marsipococcus Cockerell \& Bueker 1930, Milviscutulus Williams \& Watson 1990 y Ceronema Maskell 1895, los cuales presentan especies consideradas plagas agrícolas específicamente de cultivos de olivo y cítricos en el Nuevo y Viejo Mundo (Trjapitzin y RuízCancino 1997; Nikolaevna y Ruíz-Cancino 2011; Prado et al. 2015). Se cree que probablemente la introducción de $D$. elegans desde África al Neotrópico sea consecuencia de su uso para el control biológico de las escamas blandas plagas de los cítricos y olivos. En Argentina, los Estados Unidos y algunos países europeos y del Medio Oriente esto fue lo que ocurrió cuando $D$. elegans se liberó intencionalmente como potencial controlador biológico (Trjapitzin y RuízCancino 1997; Nikolaevna et al. 2017). Hoy se conoce que esta especie de encírtido también ataca escamas blandas asociadas a otros hospederos vegetales tales como Ficus benjamina L. (Moraceae) y Psidium guajava L. (Myrtaceae) (Trjapitzin y Ruíz-Cancino 1997; Nikolaevna y RuízCancino 2011). Recientemente, Nikolaevna et al. (2017) reportaron el ataque de $D$. elegans a la escama Parasaissetia nigra (Nietner) (Hemiptera: Coccidae) asociada a la planta hemiparásita Phoradendron quadrangulare Kunth (Griseb) sobre Acacia farnesiana L. (Willd.) (Fabaceae).

Diversinervus elegans fue citada por primera vez para Colombia de un registro reportado por Vélez en 1989, el cual es incluido en el catálogo de Himenópteros Calcidoideos De Santis y Fidalgo (1994), donde este taxón como especie tipo es la única especie que se incluye para el género. En el Museo Entomológico Francisco Luis Gallego
(MEFLG) de la Universidad Nacional de Colombia sede Medellín, la especie se encuentra registrada para la ciudad de Medellín (Antioquia, Colombia) bajo el número de catálogo 1801-1.

En este trabajo se presenta el segundo registro que se tiene de $D$. elegans luego de casi tres décadas después de su primer reporte en el país a partir de un ejemplar hembra (Fig. 1) recolectado en la ciudad de Bogotá (Colombia) en un parque de uso público al nororiente de la ciudad (Parque la Vida, Localidad Usaquén, N4 44.181' W74 $02.065^{\prime}$ ). El ejemplar fue capturado con red entomológica sobre una especie arbórea nativa de uso ornamental en Bogotá comúnmente conocida como guayacán de Manizales ( $\mathrm{La}$ foensia acuminata Vand, Lythaceae). La hembra de D. elegans (Fig. 1) se reconoce por la siguiente combinación de caracteres: 1. la forma mirmecomorfa de su cuerpo la cual es considerada característica dentro de Encyrtidae; 2. La presencia de dos penachos de pelos negros largos en el mesoescudo y escutelo y 3 . Un frontovértice expandido en una cresta frontal (Fig. 1) (Trjapitzin y Ruíz-Cancino 1997).

Aunque se desconoce el hospedero específico de $D$. elegans en Bogotá, se cree que la especie esté parasitando algunos cóccidos probablemente del género Ceroplastes como $C$. cundinamarcensis Mosquera reportado para el guayacán de Manizales en esta ciudad (Mahecha et al. 2010). Especies de Ceroplastes como C. floridensis Comstock y C. rusci (Linnaeus) han sido previamente registradas como hospederos de D. elegans (Trjapitzin y Ruíz-Cancino 1997). No obstante, en Colombia la especie se reporta colectada de Saissetia sp (ejemplar consignado en MEFLG. No. catálogo 1801-1).

\section{AGRADECIMIENTOS}

Los autores agradecen a Diego Martínez y Jhon Albeiro Quiroz por facilitar la información sobre los ejemplares de $D$. elegans depositados en colección entomológica del Museo Entomológico Francisco Luis Gallego (MEFLG) y a Andrés Sánchez por proporcionar la información del Catálogo de Himenópteros Calcidoideos escrito por De Santis y Fidalgo (1994).

\section{LITERATURA CITADA}

De Santis, L. y P. Fidalgo. 1994. Catálogo de Himenópteros Calcidoideos. Serie de la Academia Nacional de Agronomía y Veterinaria (13). Buenos Aires, Argentina. Mahecha, G.E., F. Sánchez Hurtado, J.A. Chaparro Guerra, 
H.G. Cadena Carreño, G. Tovar Corzo, L.A. Villota Ojeda, L. A., G.M. Lizcano, J.A. Castro, F.B. Polanía y M.A. Quintero (Eds). 2010. Arbolado urbano de Bogotá. Identificación, descripción y bases para su manejo. (Primera ed.). Alcaldía Mayor de Bogotá, D.C., Secretaría Distrital de Ambiente, Jardín Botánico de Bogotá José Celestino Mutis. Bogotá, Colombia.

Nikolaevna, S.M y E. Ruíz-Cancino. 2011. Parasitoides (Hymenoptera: Chalcidoidea) de Coccus (Hemiptera: Coccidae) asociados a Citrus en México. Dugesiana, 18(1): 65-72

Nikolaevna, S.M., E. Ruíz-Cancino y J.M. CoronadoBlanco. 2017. Primer registro de Diversinervus elegans silvestri (Hymenoptera: Encyrtidae) en el estado de Tamaulipas, México, y otros parasitoides de la escama Parasaissetia nigra (Nietner) (Hemiptera: Coccidae). Revista Entomología Mexicana, 4: 770-773.

Recibido: 16 de julio de 2018

Aceptado: 17 de diciembre de 2018

Primero en línea: 20 de diciembre 2018

Online First Publication: 20th December 2018
Noyes, J.S. 2018. Universal Chalcidoidea Database-Natural History Museum. http://www.nhm.ac.uk/our-science/ data/chalcidoids/database. Fecha de consulta: 08 Abril de 2018.

Prado, E., T.M. Alvarenga y L.V.C. Santa-Cecilia. 2015. Parasitoids associated with the black scale Saissetia oleae (Olivier) (Hemiptera: Coccidae) in olive trees in Minas Gerais State, Brazil. Acta Scientiarum Agronomy, 37(4): 411-416.

Trjapitzin, V.A. y E. Ruíz-Cancino. 1997. Diversinervus elegans Silvestri (Hymenoptera: Chalcidoidea: Encyrtidae), un parasitoide de cóccidos (Homoptera: Coccoidea: Coccidae) en México. CEIBA, 38(2): $151-155$.

Trjapitzin, V.A., S.N. Myartseva, E. Ruíz-Cancino E. y J.M. Coronado-Blanco. 2008. Clave de géneros de Encyrtidae (Hymenoptera: Chalcidoidea) de México y un catálogo de las especies. Serie Avispas Parasíticas de Plagas y otros Insectos No. 4. Universidad Autónoma de Tamaulipas, Ciudad Victoria, Tamaulipas, México.

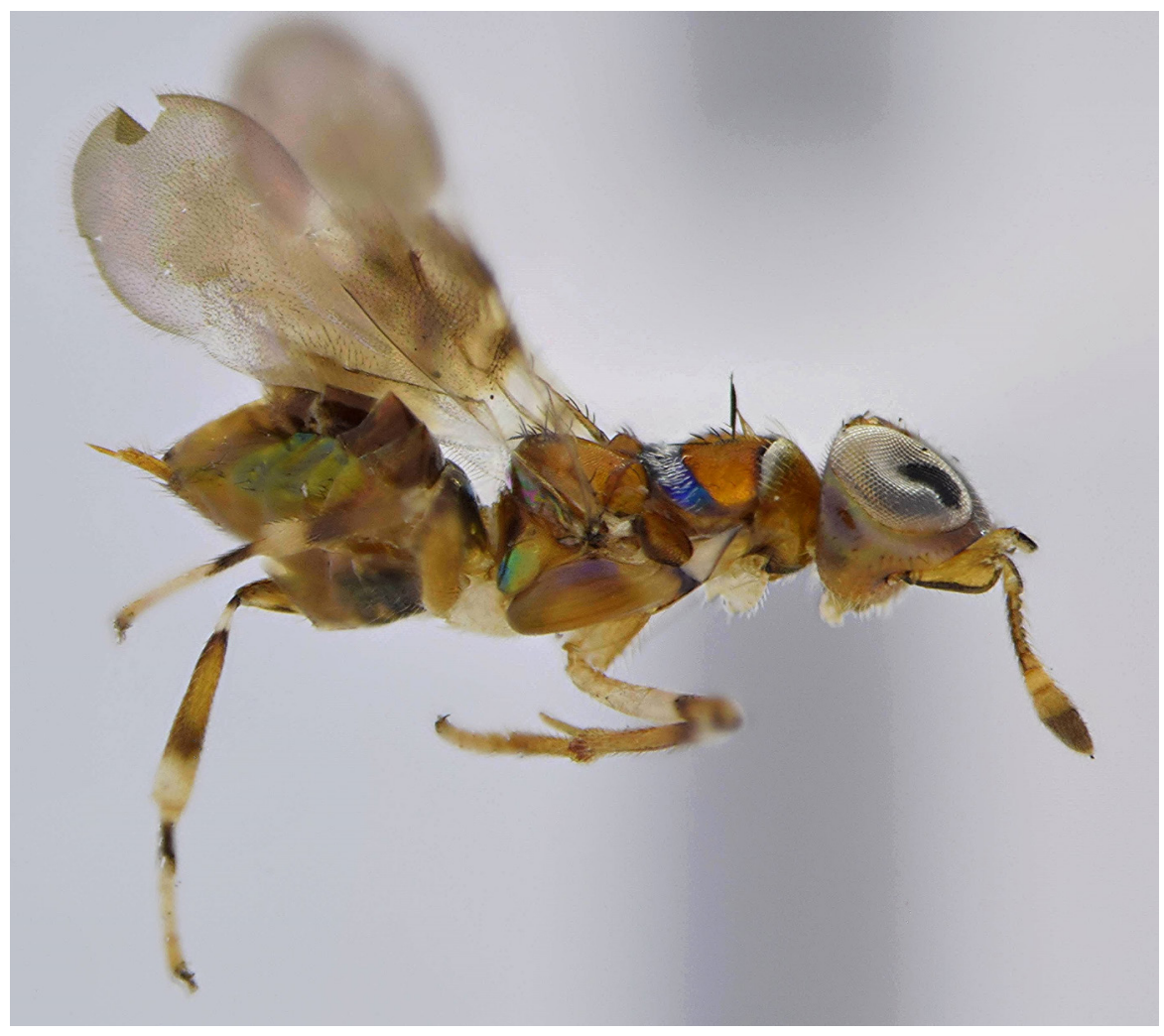

Figura 1. Hembra de Diversinervus elegans Silvestri colectada en la ciudad de Bogotá. 